\title{
Sapporo Virus
}

National Cancer Institute

\section{Source}

National Cancer Institute. Sapporo Virus. NCI Thesaurus. Code C112415.

A species of non-enveloped viruses that have characteristic cup-shaped depressions on their spherical capsid surface, with a distinctive structure of "Star-of-David" configuration, in the Caliciviridae family and Sapovirus genus. The genome is composed of singlestranded, positive-sense RNA. Sapporo viruses are found in humans and cause gastroenteritis mainly in young children. Sapporo viruses are transmitted via oral ingestion. 